\title{
Improving archaeological site-analysis: A rampart in the middle Orkhon Valley investigated with combined geoscience techniques
}

\author{
Christoph Grützner (1), Birte Ahrens (2), Jan Bemmann (2), Riccardo Klinger (3), Norbert Klitzsch (4), Sven \\ Linzen (5), Sonja Mackens (6), Martin Oczipka (7), Henny Piezonka (2), and Brigitta Schütt (3) \\ (1) RWTH Aachen, Neotectonics and Natural Hazards Group, Aachen, Germany (c.gruetzner@nug.rwth-aachen.de), (2) \\ Rheinische Friedrich-Wilhelms-Universität Bonn, Vor- und Frühgeschichtliche Archäologie, Bonn, Germany, (3) FU Berlin, \\ Physische Geographie, Berlin, Germany, (4) RWTH Aachen, Applied Geophysics and Geothermal Energy, Aachen, Germany, \\ (5) IPHT, Photonische Systeme, Jena, Germany, (6) Blücherstraße 31, Wiesbaden, Germany, (7) DLR, Optische \\ Informationssysteme Sensorkonzepte und Anwendungen, Berlin, Germany
}

The Orkhon Valley in Central Mongolia has joined the World Heritage list in 2004. It hosts multiple archaeological sites from Paleolithic to Recent which allow reconstructing the settlement history in this part of the Steppe landscape. In the BMBF project "Geo-Archaeology in the Steppe - Reconstruction of Cultural Landscapes in the Orkhon valley, Central Mongolia" we are enhancing the knowledge about ancient cultures like the Uighur, Turks and Mongols and their geographic footprint in the center of Mongolia.

Several small ramparts and Kheregsuurs were investigated in field campaigns from 2008 - 2010 beside the famous Khar-Balgas and Karakorum sites. Rampart MOR-2 (Dörvölzhin) in the Middle Orkhon Valley was hard to classify due to the lack of sufficient archaeological surface findings and its role in a manifold of walled enclosures from different times in the study area remained unclear. A first insight into topographical setting and morphometry of the rampart was gathered with an Octocopter equipped with a high resolution range finder camera, which could achieve a spatial resolution in the order of $2.5 \mathrm{~cm}$ for a DEM. Ground penetrating radar, SQUID magnetometry, and electric resistivity measurements (capacitive coupled geoelectrics) were thereafter used to characterize the sediment distribution of the inner part of the enclosure and the ramparts themselves. The data allows drawing comparisons to other sites in the Orkhon Valley regarding the construction of the wall. However, man made sub-surface structures or bigger finds could not be detected, but magnetics discovered areas with an accumulation of small artificial particles. Sediment cores were drilled in a nearby meander, covering 3000 years BP. The analysis of the strata in terms of elemental composition (P, N, Mn, Fe, etc.) revealed an increase of organic content in medieval times whereas the allochthonous filling of the back water must have started around the beginning of the first millennium AD. Since comparable sites are located nearby, we assume a dating in the Uighur period. This means that MOR-2 is the furthermost walled structure in the peri-urban area of Khar-Balgas, situated along the major travelling route through the Orkhon Valley in a favorable situation regarding the surrounding landscape. Yet the specific usage of this walled enclosure remains more or less unclear and needs further analysis. 